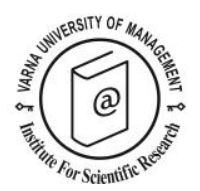

\title{
Virtual reality in the hotel industry: assessing the acceptance of immersive hotel presentation
}

\author{
Kai Israel ${ }^{1}$, Dieter K. Tscheulin ${ }^{2}$ and Christopher Zerres ${ }^{3 *}$
}

Received: 16/02/2018 Accepted: 28/07/2018

\footnotetext{
1 University of Applied Sciences Offenburg, Department of Media and Information, Badstraße 24, 77652 Offenburg, Germany

${ }^{2}$ University of Freiburg, Department of Business Administration, Platz der Alten Synagoge, 79085 Freiburg, Germany

3 University of Applied Sciences Offenburg, Department of Media and Information, Badstraße 24, 77652 Offenburg, Germany. Phone: 0049 7812054749, E-mail: christopher.zerres@hs-offenburg.de

* Corresponding author
}

\section{Abstract}

In the hotel industry, it is crucial to reduce the inherent information asymmetry with regard to the goods offered. This asymmetry can be minimised through the use of smartphone-based virtual reality applications (SBVRs), which allow virtual simulation of real experiences and thus enable more efficient information retrieval. The aim of the study is to determine for the first time the user acceptance of these immersive hotel presentations for assessing the performance of a travel accommodation. For this purpose, the Technology Acceptance Model (TAM) was used to explain the acceptance behaviour for this new technology. A virtual reality application was specially developed, in which the participants could explore a hotel virtually. A total of 569 participants took part in the study. The structural equation model and the hypotheses were tested using a Partial Least Squares (PLS) analysis. The results illustrate that the immersive product experience leads to more efficient information gathering. The perceived usefulness significantly affects the attitude towards using the technology as well as the intention to use it. In contrast to the traditional TAM, the perceived ease of use of SBVRs has no effect on the perceived usefulness or attitude towards using the technology.

(C) 2019 Varna University of Management. All rights reserved

Keywords: Virtual reality, User acceptance, Smartphone, Immersive experiences, Travel accommodation, Telepresence

Citation: Israel, K., D. Tscheulin and C. Zerres (2019) Virtual reality in the hotel industry: assessing the acceptance of immersive hotel presentation. European Journal of Tourism Research 21, pp. 522

\section{Introduction}

In the hotel industry, product presentation is an essential marketing instrument (Bilgihan et al.,
2015). Compared to other products, it is often difficult for the guest to evaluate the quality of travel accommodation prior to purchase (Zhou 
\& Lin, 2012; Guttentag, 2010; Soopramanien et al., 2007). In addition, it is becoming increasingly important for companies in this industry (e.g. hotels, travel agencies, booking portals) to provide new product presentations in order to differentiate themselves from competitors (Bilgihan et al., 2016). Virtual reality technology offers a completely new form of product visualisation which could extensively change the presentation of hotels in the future (Law et al., 2014; Guttentag, 2010). The unique feeling of being in a different place makes the hotel presentation an immersive product experience in which the user merges with virtual reality (Buhalis \& Law, 2008). The virtual reality industry is already experiencing high double-digit annual growth rates, and the global market volume is expected to reach 80 billion dollars in 2025 (Goldman Sachs, 2016). This trend is being accelerated by the permanent development of new virtual reality systems by global technology companies (e. g. Google, Facebook, Microsoft). Facebook, in particular, is investing heavily in virtual reality technology and has set itself the goal of ensuring that one billion users will use this new technology in the future (Morris, 2017). The increasing performance of smartphones is making a major contribution to this strong growth. According to current forecasts for 2021, the worldwide distribution of smartphone-based virtual reality systems is over 225 million units (PriceWaterhouseCoopers, 2017). There is little doubt that virtual reality technology will change hotel marketing in the future and it will become essential for communication (Tussyadiah et al., 2018; Guttentag, 2010). Some well-known hotel chains (e. g. Hilton, Marriott, Thomas Cook, Best Western) are already starting to use this technology for hotel presentation.

Since the creation of such interactive hotel presentations is very complex and costintensive, the question arises for hotel operators and travel agencies of whether these technology investments are worthwhile (Okumus et al., 2017). An important criterion for any technology is user acceptance. Only if a technology offers additional value are customers willing to use it. Consequently, it is economically important for hotel providers and travel agencies to determine whether smartphone-based virtual reality applications
(SBVRs) are perceived by potential guests as a useful source of information that facilitates the assessment of travel accommodation. This important practical issue has not yet been addressed by research. In order to close this gap, our study examines for the first time the role of hotel presentations with SBVRs in the customer's assessment of travel accommodation. Based on the Technology Acceptance Model (TAM), the two central factors of perceived usefulness and ease of use are investigated to determine how these influence the intention to use the technology. In addition, we analyse the suitability of SBVRs for the assessment of a travel accommodation and investigate the effects on perceived usefulness of the immersive feeling of being there. The findings of our study provide a contribution to the research field concerning users' perceptions of benefits of SBVRs within the hotel industry, and can serve as a basis for future marketing investment decisions for hotel operators and travel agencies.

\section{Literature review and hypotheses}

Smartphone-based virtual reality

As a result of the ongoing development in this extremely dynamic area, various definitions of virtual reality (systems) exist in the literature (Fuchs et al., 2011; Guttentag, 2010; Burdea \& Coiffet, 2003). From a technical point of view, in accordance with Cruz-Neira et al. (1993), in this paper we define a virtual reality system as follows: "A [smartphone-based] VR system is one which provides real-time viewer-centered head-tracking perspective with a large angle of view, interactive control, and binocular display" (Cruz-Neira et al., 1993, p. 135). On a functional level, virtual reality is defined as: "the use of a computer-generated 3D environment called a 'virtual environment' (VE) - that one can navigate and possibly interact with, resulting in real-time simulation of one or more of the user's five senses." (Guttentag, 2010, p. 638).

\section{Technology acceptance model}

The TAM is an established method for examining the user's acceptance of new technologies (Marangunić \& Granić, 2015; King $\& \mathrm{He}, 2006$; Legris et al., 2003). Based on the theory of reasoned action (Fishbein \& Ajzen, 1975), which explains the relationship between 
attitudes and behavioural intention, Davis (1989) developed a model to explain the user's acceptance of information systems. In his research Davis stated that the intention to use a technology is mainly dependent on the individual's attitude towards using information technology, which is primarily influenced by the cognitive factors of perceived usefulness as well as the ease of use (Davis et al., 1989). He defined the perceived usefulness as "the degree to which a person believes that using a particular system would enhance his or her job performance", whereas he defined ease of use as "the degree to which a person believes that using a particular system would be free of effort" (Davis, 1989, p. 320). The TAM has been used in many studies. Also the quality of the model has been verified and its statistical reliability has been proved (Marangunić \& Granić, 2015; Legris et al., 2003; King \& He, 2006). The TAM model has been established in technology acceptance research and has been further specified in various ways. As a result, the perceived usefulness (TAM2) and the perceived ease of use (TAM3) have been extended by additional determinants (Venkatesh \& Davis, 2000; Venkatesh \& Bala, 2008). In contrast, the Unified Theory of Acceptance and Use of Technology (UTAUT) and the subsequent model (UTAUT2) focused on determining further factors that directly influence the user's behavioural intention to use a technology (Venkatesh et al., 2003; Venkatesh et al., 2012). Despite the continuous integration of new factors and the resulting increase of model complexity, all acceptance models agree that both the perceived usefulness (UTAUT $\hat{=}$ performance expectation) and the perceived ease of use (UTAUT $\triangleq$ effort expectation) are essential determinants which influence the user's behavioural intention. This similarity emphasises the importance of these two factors in technology acceptance research. Therefore, the present study is based on the traditional TAM model, which is extended by the unique feeling of being there - namely telepresence - and the construct of tasktechnology fit.

In nearly all situations, consumers make decisions while facing some uncertainties (Taylor, 1974). In order to minimise the risk of a wrong decision, the consumer will look for information that is relevant to the purchase (Hwang et al., 2013; Shim \& Lee, 2011; Cho \& Lee, 2006; Taylor, 1974). Travel accommodations are mostly experience goods, meaning potential guests have difficulty in evaluating the offering (Bilgihan et al., 2015; Zhou \& Lin, 2012; Guttentag, 2010). Therefore, more effort is necessary for searching and planning to ensure that a satisfactory buying decision is made (Xiang et al., 2015; Hwang et al., 2013). Sharifpour et al. (2014) proved in their research that the perceived risk in the booking process is minimised by the provided product information if this information is communicated in a credible way and is easy to access. Suitable instruments to reduce information asymmetries are SBVRs, which support potential guests during their individual search and planning phase by new visualisation possibilities. In particular, through the realistic presentation of the hotel and the intuitive interaction, the guest has the feeling of being there (Buhalis \& Law, 2008). virtual reality applications provide potential guests in advance with relevant information that they need to evaluate the hotel offer. Interactive virtual product presentations are considered by consumers as particularly useful in information gathering, and can improve their attitude towards using the technology (Kim \& Forsythe, 2008; Lee et al., 2006). Davis (1989) states that the perceived usefulness also has a direct influence on the intention to use a technology. This fact is based on the assumption that an information system which offers the user efficiency advantages will be repeatedly used by him (Davis, 1989; Davis et al., 1989). As previous tourism research indicates, smartphone applications support travellers in gathering information. Tourism-related augmented reality applications, in which the camera picture of the smartphone is superimposed with location-based additional information in real time, are considered by travellers to be a useful source of information (Kim \& Hyun, 2016; Kourouthanassis et al., 2015). In contrast to SBVRs, the information search in augmented reality applications is limited to the immediate environment. Because the virtual information is presented as part of the real world, the traveller must be physically present at the location. With SBVRs this 
Virtual reality in the hotel industry: assessing the acceptance of immersive hotel presentation.

physical presence can be simulated virtually to provide travellers with valuable information before their arrival. As the researchers state, this perceived usefulness of the information provided is an important factor that positively influences the travellers' intention to reuse the application (Kim \& Hyun, 2016). Prior studies in the context of the virtual world 'Second Life' have also revealed that the virtual reconstruction of a travel destination supports users in travel planning (Huang et al., 2016; Huang et al., 2013). Inside the virtual world, users are able to interact with the virtual environment through avatars to gather information about the travel destination. This virtual experience enables users to get a realistic impression of the travel destination in advance, which facilitates the travel decisionmaking process (Huang et al., 2013). Therefore, virtual worlds offer the users efficiency advantages in information gathering and simplify travel planning. As the researchers confirmed, the perceived usefulness of a virtual world is thus an important factor which positively affects the intention to use it (Huang et al., 2016; Huang et al., 2013). In line with these findings, we assume that potential guests can better evaluate the value offered by a travel accommodation by using an SBVR. Furthermore, this will positively affect the attitude towards using the SBVR as well as the intention to use it.

$H_{1}$ : $\quad$ The perceived usefulness of an SBVR has a positive effect on the attitude towards using the technology

$\mathrm{H}_{2}$ : $\quad$ The perceived usefulness of an SBVR has a positive effect on the intention to use the technology

Furthermore, the ease of use of the information system leads to a higher user acceptance (Davis et al., 1989, Davis, 1989). The more easily such a system can be operated by the user, the higher is the likelihood that the user will accept the information system and thus use it in the future. With regard to the virtual reality application for assessing hotel offers this means that interaction with the application needs to be easy. Moreover, the potential guest should be able to intuitively operate the system. Chung et al. (2015), in their study dealing with the user acceptance of augmented reality applications, show that a simple interaction leads to a higher perceived usefulness of the information presentation through better ease of use. The same applies to virtual dressing rooms in which easy usability of the virtual application has a significant influence on the perceived usefulness (Kim \& Forsythe, 2008). Also, Rauniar et al. (2014) were able to demonstrate in their study on social media usage that simple operations and interaction are important design criteria which lead to good usability and thereby increase the perceived usefulness. Based on the above argumentation and the previous findings, the hypothesis to be tested is as follows:

$H_{3}$ : $\quad$ The perceived ease of use of an SBVR has a positive effect on the perceived usefulness

In addition, the perceived ease of use has a significant influence on the attitude towards using the technology. In the case of internet applications, ease of use is an essential feature that leads to a positive attitude towards using the technology and thus to a higher intention to use it (King \& He, 2006). The perceived ease of use of the virtual reality application also minimises intrinsic usage barriers. In particular, the positive user experience resulting from the simple usability leads to a positive attitude towards the information system (Venkatesh, 2000). Consequently, the attitude towards using the virtual reality application can be positively influenced if the user perceives the system to be easy to use. Ayeh et al. (2013) stated that for internet applications the perceived ease of use is of particular importance. This finding coincides with research results in the online field, which demonstrate the significant positive influence of perceived ease of use on the attitude towards using a technology (Chung et al., 2015; Park, 2009; Lee et al., 2006). Accordingly, it can be assumed that the user is more open-minded towards the virtual reality application if it is easy use, which positively influences the attitude towards using it.

$H_{4}$ : The perceived ease of use of an SBVR has a positive effect on the attitude towards using the technology 
Based on the theory of reasoned action, the attitude towards using a technology is a major determinant of the intention to use a technology. The consumer's attitude towards using a technology is based on their beliefs about the technology (Fishbein \& Ajzen, 1975). When transferred to the virtual reality application, this means that if the user is convinced that the use of the virtual reality application could lead to a positive effect, the willingness to use the application increases (Bertrand \& Bouchard, 2008). Accordingly, the individual attitude towards using the technology influences the intention to use it. In this respect, Cheng \& Cho (2011) identified the attitude towards using a technology as the main influence factor that must be taken into account when introducing an information and communication technology (ICT) in a travel company. Only if the employees develop a positive attitude towards using the ICT will they use it in the future (Cheng \& Cho, 2011). A similar behaviour can be found in the online and offline information search within the travel planning process. If the information can be accessed using different technologies, the attitude towards using one of the different technologies is the fundamental factor influencing the intention to use it. In the case of travel planning, users will use the technology which they are convinced will be most useful for the information search (Ayeh et al., 2013). This leads to the following research hypothesis:

$H_{5}$ : $\quad$ The attitude towards using an SBVR has a positive effect on the intention to use the technology

\section{Telepresence}

Telepresence is often an essential feature associated with the online domain in research (Kim \& Hyun, 2016; Huang et al., 2012; Hyun \& O'Keefe, 2012; Lee \& Letho, 2013; Debbabi et al., 2010; Klein, 2003). Due to the steady growth in online trading, it is becoming increasingly important for marketing managers to simulate a direct product experience through virtual technologies (Klein, 2003). The same applies to the hotel industry, where the hotel experience can only take place during a real visit (Guttentag, 2010). Through the new visualisation capabilities of SBVRs, hotel providers can offer additional information to the potential guest to facilitate the evaluation of a travel accommodation (Debbabi et al., 2010). Above all, a realistic presentation of a hotel gives the user the feeling of being there. This feeling is described in the literature as telepresence and is the feeling perceived in virtual environments by the user (Klein, 2003; Nowak \& Biocca, 2003). Steuer (1992) argues that the immersion is always created according to two separately perceived realities. Besides a physical reality in which the user is actually located, the computer-generated reality is simultaneously perceived by the user. Telepresence, therefore, represents the degree to which the user has the perceived feeling of being in a virtual rather than in a physical reality (Sanchez-Vives \& Slater, 2005; Steuer, 1992). In our study, telepresence is conceptualised as an influencing factor that helps to quantify the user's feeling of being in a virtual setting. As research on the influence of telepresence on the product experience demonstrates, the virtual product presentation is a meaningful marketing method which increases the consumer's product experience (Debbabi et al., 2010; Klein, 2003). Within the scope of destination marketing previous research has revealed that the immersive feeling of being there increases the interest in a destination (Choi et al., 2016; Tussyadiah et al., 2018; Tussyadiah et al., 2017; Marasco et al., 2018). As the researchers stated, the readiness to actually visit a travel destination increases if travellers can explore the travel destination virtually in advance (Tussyadiah et al., 2018; Tussyadiah et al., 2017). Taking into account the technical possibilities, SBVRs are therefore very good for illustrating the hotel offer to potential guests. In particular, the realistic presentation of the hotel and the intuitive interaction of the system offer the user an additional benefit (Huang et al., 2012; Buhalis \& Law, 2008; Jiang \& Benbasat, 2007). By integrating audio-visual content elements (e.g. pictures, videos, a soundscape of the hotel), hotel providers can give potential guests a realistic impression of the hotel. This additional information supports the potential guest in travel planning and facilitates the decision-making process (Huang et al., 2016). Based on the previous findings the hypothesis to be tested is as follows: 
Virtual reality in the hotel industry: assessing the acceptance of immersive hotel presentation.

$H_{6}$ : The telepresence of an SBVR has a positive effect on the perceived usefulness

\section{Task-technology fit}

The lack of task relation in the classic TAM is often criticised (Dishaw \& Strong, 1999; Nance \& Straub, 1996). In this respect, the TAM is capable of explaining the perceived usefulness as a result of using the information system, as well as the influence of the perceived ease of use. However, the model cannot be used to determine the suitability of the technology for fulfilling a given task. Goodhue \& Thompson (1995) stated that the best results can be achieved if the task to be achieved is solved with the given technology. Based on this assumption, they developed the general tasktechnology fit theory, which explains how a technology helps the user to solve a task (Goodhue \& Thompson, 1995). For example, Dishaw \& Strong (1999) were able to demonstrate that, compared to the individual models, the combination of the task-technology fit and the TAM lead to more meaningful results. The adaptation of a new technology therefore depends on the individual perception of whether it is suitable for accomplishing the task (Lam et al., 2007; Burton-Jones \& Hubona, 2005). In the online field, this relationship has been proven in several studies (Lee \& Lehto, 2013; Chang, 2010). The tasktechnology fit has a significant influence on the perceived usefulness, particularly, in the case of intelligent bidding systems in online auctions. The better such an intelligent system considers the user's requirements, the higher is the perceived usefulness (Chang, 2010). The same findings have been produced in the e-learning field (Lee \& Lehto, 2013). We assume a similar relationship in our research. The more suitable the virtual reality application is for assessing a hotel, the higher the perceived usefulness.

$H_{7}$ : The perceived task-technology fit of an SBVR has a positive effect on the perceived usefulness

\section{Proposed research model}

Based on the previous discussion we propose a research model describing the user acceptance of SBVRs for the presentation of hotel offers. In accordance with the TAM, the influence of perceived ease of use and perceived usefulness on the user's attitude towards using SBVRs and the behavioural intention to use SBVRs are examined. In addition, the proposed research model takes into account the constructs of telepresence and task-technology fit, which are assumed to have a positive influence on the user's perceived usefulness. The proposed research model of this study is shown in Figure 1.

\section{Method}

\section{Operationalisation}

The constructs of perceived usefulness (five items) and perceived ease of use (four items) were adapted from Davis (1989) and transferred to the present research object of SBVRs. The same applied to the operationalisation of the construct attitude towards using (three items), which is based on Venkatesh et al. (2003). The assessment of the intention to use the technology was measured

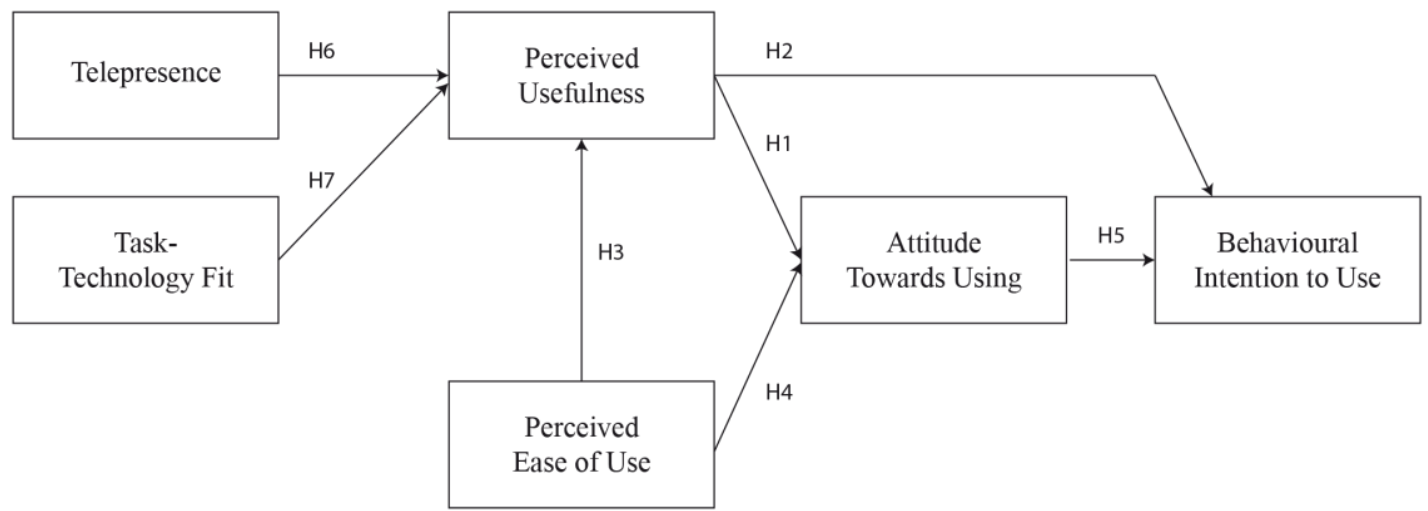

Figure 1. Research model 
by three items derived from the studies of Venkatesh (2000) and Lee \& Lehto (2013). Based on the study by Klein (2003) telepresence was quantified by three items. Furthermore, we adapted four items from Hoehle \& Huff (2012) as well as Klopping \& McKinney (2004) for the operationalisation of the task-technology fit construct. The individual items were assessed with a seven-point Likert scale ranging from "strongly disagree" (1) to "strongly agree" (7).

\section{Development of the virtual reality application}

The SBVR is a new way of communication in the hotel industry. Accordingly, it could not be assumed that all study participants were able to evaluate the potential of SBVRs. Therefore, an application was specifically developed for our study, in which the participants could explore a hotel virtually. As a data basis for the application, 43 professional 360-degree panorama photographs provided by a hotel were used. These images were exported using the 3D visualisation software Unity for the Samsung Galaxy S7 and the related glasses Gear VR. The navigation between the individual panoramic views was realised with hotspots (Figure 2). In addition to this hotspot navigation, an extra main menu was implemented, which could optionally be displayed by the user. This menu allowed the user to navigate directly to certain points of interest (e.g. restaurant, beach, room) in the hotel facility.

\section{Data collection and design of the study}

A pre-test of the questionnaire and the virtual reality application was conducted to validate the questionnaire and to reveal possible errors in the virtual reality application. For our study, we used various sources to acquire study participants. As well as all students at a technical university in Germany, all employees of the university were personally invited to participate in the study by e-mail. In addition, further participants were acquired in cooperation with several companies, institutions and social clubs. As an incentive, a tablet was raffled among all the participants. The study was conducted from November 2016 to March 2017 in an air-conditioned laboratory. The sample included 569 persons, consisting of 334 students and 235 non-students who voluntarily participated in the study.

The study was divided into four phases. In the first phase, the subjects were asked to watch an introductory video explaining some basic functions of virtual reality glasses and the aim of the study. In the second phase, the study

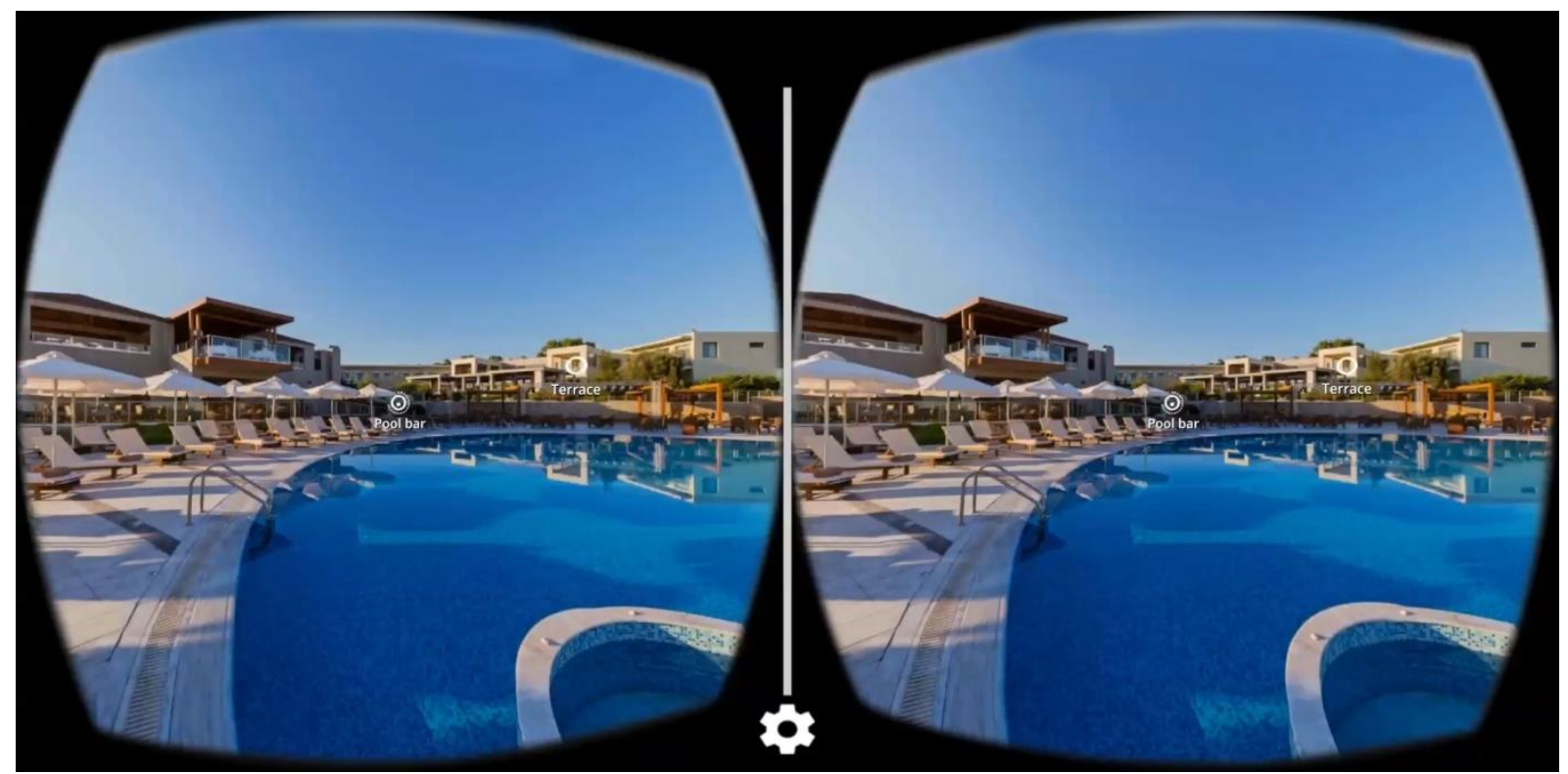

Figure 2. Virtual reality application screenshot (example) 
Virtual reality in the hotel industry: assessing the acceptance of immersive hotel presentation.

participants received a questionnaire, in which their travel habits, their sociodemographic data, and their previous experiences with virtual reality were recorded. At the beginning of the third phase, the subjects were given the virtual reality glasses. After the individual configuration of the virtual reality glasses, an audio playback started in which the scenario was described. In this scenario, the participants had to imagine that they were planning a twoweek all-inclusive trip and that they would use an SBVR to gain information about a hotel. The use of the virtual reality application was limited to ten minutes. However, the participants could finish the tour earlier by discontinuing their use of the virtual reality glasses. In the fourth phase, a second questionnaire was given to the participants in order to assess the hotel virtual reality application.

\section{Data analysis process}

Of the 569 collected questionnaires, 37 had to be eliminated because of multiple missing values. Thus, 532 complete sets of data were used for the analysis. The characteristics of the participants are presented in Table 1. As the

Table 1. Characteristics of respondents $(n=532)$

\begin{tabular}{|c|c|c|c|}
\hline & Characteristics & Frequency & Percentage (\%) \\
\hline \multirow[t]{2}{*}{ Gender } & Female & 246 & 46.2 \\
\hline & Male & 286 & 53.8 \\
\hline \multirow[t]{6}{*}{ Age } & Under 20 & 20 & 3.8 \\
\hline & $20-29$ & 312 & 58.6 \\
\hline & $30-39$ & 90 & 16.9 \\
\hline & $40-49$ & 43 & 8.1 \\
\hline & $50-59$ & 39 & 7.3 \\
\hline & Over 60 & 28 & 5.3 \\
\hline \multirow[t]{4}{*}{ Employment status } & Student & 316 & 59.4 \\
\hline & Employees & 184 & 34.6 \\
\hline & Pensioner & 17 & 3.2 \\
\hline & Others & 15 & 2.8 \\
\hline Travel Budget & Under 500 EUR & 64 & 12.0 \\
\hline \multirow[t]{5}{*}{ (per year) } & $500-1.000$ EUR & 152 & 28.6 \\
\hline & $1.000-1.500$ EUR & 121 & 22.7 \\
\hline & $1.500-2.000$ EUR & 83 & 15.6 \\
\hline & Over 2.000 EUR & 94 & 17.7 \\
\hline & Not specified & 18 & 3.4 \\
\hline \multirow[t]{3}{*}{ Last Booking } & $0-3$ months & 256 & 48.1 \\
\hline & $4-6$ months & 156 & 29.3 \\
\hline & Over 6 months & 120 & 22.6 \\
\hline \multirow[t]{2}{*}{ Smartphone owner } & Yes & 522 & 98.1 \\
\hline & No & 10 & 1.9 \\
\hline \multirow[t]{2}{*}{ Know the term VR } & Yes & 498 & 93.6 \\
\hline & No & 34 & 6.4 \\
\hline \multirow[t]{2}{*}{ VR used } & Yes & 268 & 50.4 \\
\hline & No & 264 & 49.6 \\
\hline
\end{tabular}


Israel, K., D. Tscheulin and C. Zerres (2019) / European Journal of Tourism Research 21, pp. 5-22

characteristics of the participants show, the majority of the study participants were under 30 years of age. This was due to the high proportion of students, which is critically considered in tourism research (Ok et al., 2008). However, students are open-minded towards new technologies and are often early adopters. As digital natives, they have grown up with technologies (e.g. the smartphone, the internet) and are therefore a convenient target group to assess the potential of new technologies such as SBVRs (Lee, 2014). Also, current German travel statistics show that the younger generation has a high travel readiness and on average travels the longest (Reinhardt, 2018). We therefore assume that our sample is suitable for further analysis, but we are aware of the limitations.

To determine an appropriate method for structural equation modelling, the sample size and the data normality were checked. The suitability of the sample size was assessed in accordance with the criteria proposed by Hair et al. (2014). According to this, at least 300 cases should be available for the calculation of a structural equation model with seven constructs or less. With 532 cases we fulfil this criterion; thus, the CB-SEM method as well as the PLS-SEM method would be suitable for structural equation modelling (Hair et al., 2014; Hair et al., 2011). Furthermore, the data normality was checked. The z-scores of skewness and kurtosis were calculated as a function of the sample size. To meet the criterion of data normal distribution, the $z-$ scores should be in the range \pm 2.58 (Hair et al., 2014). The evaluation of the data showed that this criterion was not fulfilled, which indicates a non-normal distribution of the data. In contrast to the CB-SEM method, structural equation modelling with the PLS-SEM method can be performed with non-normal data distribution (Hair et al., 2011). Therefore, we use the PLSSEM method in this study, which is very well suited to marketing and management information system research (Hair et al., 2011) and is also becoming increasingly important in tourism research (Barnes et al., 2016). Especially in the context of new technologies, the PLS method is suitable for the modelling of latent variables in behavioural research (Henseler et al., 2016). Hence the model estimation was performed with SmartPLS 3.2.6.

\section{Results}

Assessment of the measurement model

The assessment of the measurement model was based on internal consistency reliability, convergence validity, and discriminant validity (Hair et al., 2017). The reliability test of the internal consistency was performed using the Cronbach's alpha coefficient ( $\alpha$ ) and the composite reliability ( $\rho c)$ (Henseler et al., 2016). Table 2 shows that all values are above the required minimum values of the respective criteria; therefore, an internal consistency is given.

The convergence validity of the measurement model is examined by the outer loadings, the indicator reliability, and the average variance extracted (Table 2). A proof of the convergence validity of the measurement model is high outer loadings of those indicators which are assigned to a construct. In this respect, the outer loadings of the assigned indicators should exceed 0.707 (Hair et al., 2017). As Table 2 shows, this criterion is met by all items. In addition, the respective indicator reliability (> $0.5)$ can be determined by squaring the individual factor loadings (Hair et al., 2017). Consequently, the indicator reliability is confirmed, since all factor loadings are above the required value of 0.707 . The same applies to the average variance (AVE), which is in all cases above the minimum requirement of 0.5 (Henseler et al., 2016) (Table 2).

To determine the discriminant validity of the measurement model the Fornell-Larcker criterion is used (Fornell \& Larcker, 1981). The square root of the average variance of each construct must be higher than the intercorrelations between the constructs. The results in Table 3 show that the discriminant validity can be confirmed by using the FornellLarcker criterion. In addition, discriminant validity was verified using the heterotraitmonotrait (HTMT) ratio of correlations (Henseler et al., 2015). In the study, the conservative limit value HTMT. 85 is chosen to determine the discriminant validity (Henseler et al., 2015). The results in Table 3 show that the discriminant validity of the measurement model 
Table 2. Validity and reliability of the constructs

\begin{tabular}{|c|c|c|c|c|c|}
\hline Construct and items & Loadings & $\begin{array}{c}\text { Cronbach } \\
(\alpha)\end{array}$ & $\begin{array}{l}\text { CR } \\
\text { (pc) }\end{array}$ & AVE & $\mathbf{Q}^{2}$ \\
\hline Criteria & $>0.7$ & $>0.7$ & $>0.7$ & $>0.5$ & $>0$ \\
\hline Attitude & & 0.930 & 0.955 & 0.877 & 0.427 \\
\hline \multicolumn{6}{|l|}{ Virtual reality applications are ... } \\
\hline a very interesting technology for watching a hotel & 0.925 & & & & \\
\hline a good idea for watching a hotel & 0.951 & & & & \\
\hline a great opportunity to get an impression of a hotel & 0.933 & & & & \\
\hline Behavioural intention & & 0.908 & 0.942 & 0.845 & 0.459 \\
\hline \multicolumn{6}{|l|}{ Assuming I had virtual reality glasses, then I would .... } \\
\hline use them to virtually observe a hotel facility & 0.925 & & & & \\
\hline \multirow{2}{*}{$\begin{array}{l}\text { use them to get an impression of the hotel } \\
\text { recommend them to others who want to get an impression of the } \\
\text { hotel }\end{array}$} & 0.945 & & & & \\
\hline & 0.886 & & & & \\
\hline Usefulness & & 0.887 & 0.917 & 0.689 & 0.350 \\
\hline $\begin{array}{l}\text { Through the virtual reality application, I can more quickly } \\
\text { get an impression of the hotel }\end{array}$ & 0.757 & & & & \\
\hline Due to the virtual reality application, I can easily evaluate the hotel & 0.821 & & & & \\
\hline By using the virtual reality application, I can better evaluate the hotel & 0.846 & & & & \\
\hline I find the virtual reality application useful to watch a hotel & 0.846 & & & & \\
\hline $\begin{array}{l}\text { Overall, I find that the virtual reality application is useful } \\
\text { to get an impression of the hotel }\end{array}$ & 0.876 & & & & \\
\hline Ease of use & & 0.829 & 0.885 & 0.659 & - \\
\hline The handling of the virtual reality application was easy for me & 0.821 & & & & \\
\hline I found it hard to use the virtual reality application* & 0.779 & & & & \\
\hline The operation of the virtual reality application was simple & 0.782 & & & & \\
\hline Overall, I found the virtual reality application easy to use & 0.863 & & & & \\
\hline Telepresence & & 0.826 & 0.896 & 0.743 & - \\
\hline $\begin{array}{l}\text { While I was using the virtual reality application, I felt as } \\
\text { if I were in another world }\end{array}$ & 0.779 & & & & \\
\hline $\begin{array}{l}\text { Through the virtual simulation I had the feeling of really } \\
\text { experiencing the situation }\end{array}$ & 0.897 & & & & \\
\hline $\begin{array}{l}\text { When I navigated through the virtual world, I felt I was in a different } \\
\text { place }\end{array}$ & 0.904 & & & & \\
\hline Task-technology fit & & 0.876 & 0.915 & 0.689 & - \\
\hline \multicolumn{6}{|l|}{ Virtual reality applications are in my opinion ... } \\
\hline very suitable, if you need information about a hotel & 0.903 & & & & \\
\hline exactly the way I would like to get information about a hotel & 0.853 & & & & \\
\hline not suitable for getting information about a hotel ${ }^{*}$ & 0.798 & & & & \\
\hline a good way to get information about a hotel & 0.859 & & & & \\
\hline
\end{tabular}

Note: * reverse coded item

Table 3. Discriminant validity Fornell and Larcker (square root of the AVE in bold) and HTMT.85 criterion (grey)

\begin{tabular}{lcccccc}
\hline & Attitude & $\begin{array}{c}\text { Behavioural } \\
\text { intention }\end{array}$ & Ease of use & Telepresence & $\begin{array}{c}\text { Task- } \\
\text { technology fit }\end{array}$ & Usefulness \\
\hline Attitude & $\mathbf{0 . 9 3 6}$ & 0.744 & 0.251 & 0.448 & 0.658 & 0.775 \\
Behavioural intention & 0.684 & $\mathbf{0 . 9 1 9}$ & 0.208 & 0.462 & 0.666 & 0.779 \\
Ease of use & 0.227 & 0.186 & $\mathbf{0 . 8 1 2}$ & 0.283 & 0.229 & 0.237 \\
Telepresence & 0.390 & 0.402 & 0.242 & $\mathbf{0 . 8 6 2}$ & 0.479 & 0.531 \\
Task-technology fit & 0.597 & 0.599 & 0.200 & 0.411 & $\mathbf{0 . 8 5 4}$ & 0.793 \\
Usefulness & 0.710 & 0.706 & 0.209 & 0.457 & 0.703 & $\mathbf{0 . 8 3 0}$ \\
\hline
\end{tabular}

can also be confirmed by the HTMT method since all results are below the threshold value of 0.85 .

\section{Assessment of the structural model}

The assessment of the structural model was based on the coefficient of determination $\left(R^{2}\right)$, the predictive relevance $\left(Q^{2}\right)$, the standardised 
root mean square residual (SRMR), the strength of the path coefficients and the significance of the hypothetical relations. The interpretation of the $\mathrm{R}^{2}$ values for endogenous variables is based on the scale suggested by Chin (1998). As a result, $R^{2}$ values of 0.19 for endogenous variables are considered as weak, 0.33 as moderate, and 0.67 as substantial (Chin, 1998). With values of around 0.5 , all endogenous variables (Figure 3 ) are clearly above the threshold of 0.33 , which is required for a moderate model assessment. In order to determine the predictive relevance $\left(Q^{2}\right)$ of the structural model, the Stone-Geisser test (Stone, 1974; Geisser 1974) was carried out. The blindfolding procedure was used to determine whether the established model was suitable for the reconstruction of empirical data $\left(Q^{2}>0\right)$ (Chin, 1998). As shown in Table 2, the
Stone-Geisser criterion is met by all endogenous variables so that the predictability of the model can be established. In addition, the SRMR has a value of 0.053 , which is below the limit of 0.08 , so that the fit of the model is confirmed (Hair et al., 2017; Henseler et al., 2016).

Finally, we analysed the path coefficients of the structural model, which was necessary for the examination of the research hypotheses. While the strength of the path coefficients was calculated directly by the PLS algorithm, their significance had to be verified using the bootstrapping method. As the calculation of the path coefficients shows, all structure paths fit with the proposed relationships (Table 4). Only the strength of the relationships between perceived ease of use and perceived

Table 4. Results of hypothesis testing

\begin{tabular}{llccccc}
\hline $\begin{array}{l}\text { Hypothe } \\
\text { sis }\end{array}$ & Relationships & $\begin{array}{c}\text { Path } \\
\text { coefficient }\end{array}$ & $\begin{array}{c}\text { Confidence } \\
\text { Interval } \\
\text { (Bias Corrected) }\end{array}$ & t-Value & p-Value & Supported \\
\hline H1 Usefulness $\rightarrow$ Attitude & $0.693^{*}$ & {$[0.613,0.755]$} & 19.179 & 0.000 & Yes \\
H2 & Usefulness $\rightarrow$ Behavioural intention & $0.445^{*}$ & {$[0.340,0.545]$} & 8.485 & 0.000 & Yes \\
H3 & Ease of use $\rightarrow$ Usefulness & 0.039 & {$[-0.030,0.107]$} & 1.112 & 0.266 & No \\
H4 Ease of use $\rightarrow$ Attitude & 0.082 & {$[0.006,0.171]$} & 1.932 & 0.053 & No \\
H5 & Attitude $\rightarrow$ Behavioural intention & $0.368^{*}$ & {$[0.258,0.476]$} & 6.626 & 0.000 & Yes \\
H6 & Telepresence $\rightarrow$ Usefulness & $0.195^{*}$ & {$[0.122,0.270]$} & 5.189 & 0.000 & Yes \\
H7 & Task-technology fit $\rightarrow$ Usefulness & $0.615^{*}$ & {$[0.540,0.680]$} & 17.273 & 0.000 & Yes \\
\hline
\end{tabular}

Note: ${ }^{*} p<0.001$

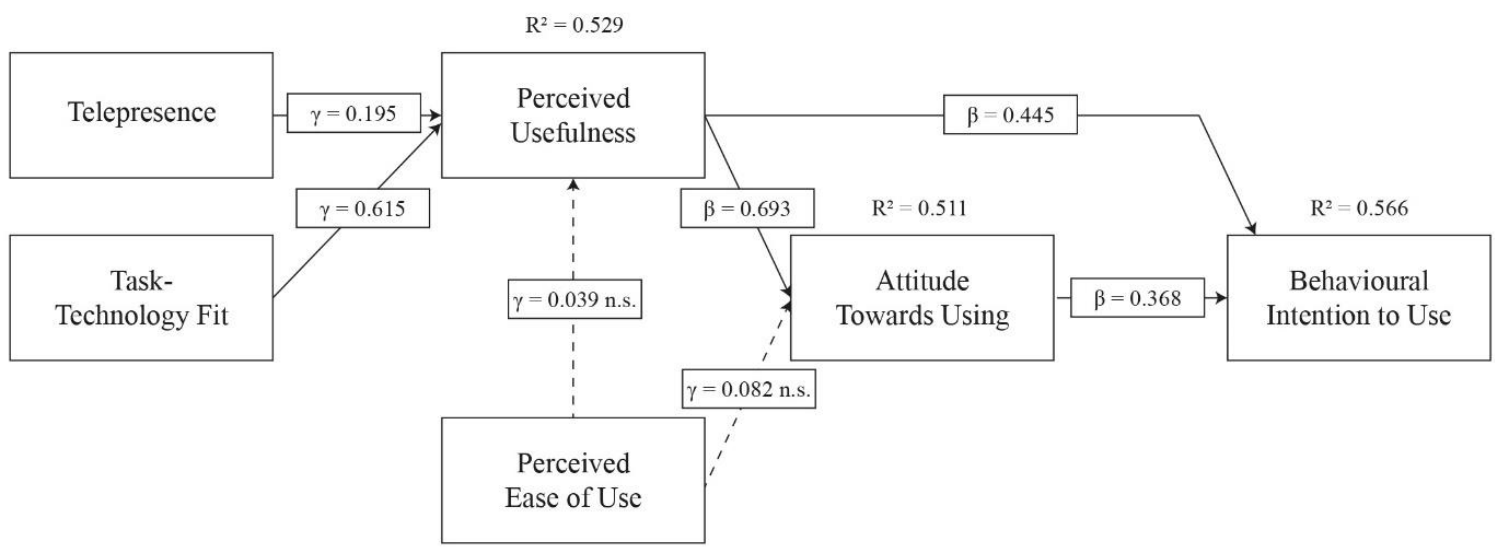

Figure 3. PLS results of the structural model 
Virtual reality in the hotel industry: assessing the acceptance of immersive hotel presentation.

usefulness as well as the attitude towards using the application are weak. In order to determine the significance of the path coefficients, a complete bootstrapping $(5,000$ subgroups) was carried out. The results of the bootstrapping procedure are listed in Table 4. Overall, the statistical significance of the path coefficients for five of the seven hypothesised relationships could be confirmed. Thus, the perceived usefulness of an SBVR has a positive effect on the attitude towards using the application $(\beta=0.693, t=19.179, p<0.001)$ as well as the intention to use it $(\beta=0.445, \mathrm{t}=$ $8.485, p<0.001)$. Furthermore, the attitude towards using the application $(\beta=0.368, t=$ $6.626, p<0.001)$ positively affects the intention to use it. The perceived usefulness is positively influenced by the factors of telepresence $(\mathrm{\gamma}=$ $0.195, \mathrm{t}=5.189, \mathrm{p}<0.001)$ and tasktechnology fit $(y=0.615, t=17.273, p<0.001)$. In contrast to the traditional TAM, we cannot confirm a significant influence of the perceived ease of use on the perceived usefulness $(\gamma=$ $0.039, t=1.112, p>0.05$ ) or on the attitude towards using the application $(\mathrm{Y}=0.082, \mathrm{t}=$ 1.932, $p>0.05$ ).

\section{Discussion}

\section{Theoretical implications}

Based on the TAM, the perceived usefulness as well as the perceived ease of use were investigated with regard to their effect on the attitude towards using the application as well as the intention to use it. As the results clearly show, the perceived usefulness is a central predictor which positively affects the attitude towards using the technology as well as the intention to use it. The result concerning the relationship between perceived usefulness and attitude towards using the technology is in accordance with Chung et al. (2015). Our study also shows that the perceived usefulness has a direct and positive effect on the future intention to use. This direct relationship is consistent with the research results of Kim \& Hyun (2016), which identify the perceived usefulness as a predicator for the future intention to use. In contrast to these two studies, our study shows that the perceived usefulness of an SBVR significantly influences both the attitude towards using the technology and the intention to use it. At the same time, our study shows there is significant relationship between the attitude towards using the technology and the intention to use it, which is also found in the context of other technologies (Chung et al., 2015; Ayeh et al., 2013; Cheng \& Cho, 2011).

In contrast to the traditional TAM, we could not confirm a significant relationship between the perceived ease of use and the perceived usefulness or the attitude towards using the application. Previous research has already stated that the perceived ease of use, in comparison to the perceived usefulness, plays a less important role concerning the acceptance of new technologies (Davis et al., 1989; Venkatesh, 2000; Huang et al., 2016; Huang et al., 2013). In addition, these weak relationships have already been discussed in literature. One explanation for these weak relationships is that the more experience a person has of using the technology, the less important is the influence of the perceived ease of use (Lee \& Lehto, 2013; Hu et al., 1999; Davis et al., 1989). In order to ascertain whether this argumentation holds for SBVRs, the relationship between the perceived ease of use and the perceived usefulness as well as the attitude towards using the application was analysed with regard to the usage experience. The first group $(n=268)$ consisted of respondents who had already used a virtual reality application before the study. This was not the case for the second group $(n=264)$. However, we could not confirm a significant effect on the perceived usefulness or attitude towards using the application for the group of experienced respondents nor for the group of inexperienced respondents. Therefore, in our study, usage experience does not explain the weak effects of the perceived ease of use. The second approach is based on the study results of Subramanian (1994), who explains the insignificant effect of the perceived ease of use is due to the inherent ease of use of a technology. Accordingly, the perceived ease of use has little or no effect on the acceptability if the technology is inherently easy to use (Subramanian, 1994; Liu et al., 2010;). Our results seem to support this argumentation because the mean value of the items for the perceived ease of use indicate a high agreement $(\mathrm{MV}=6.79, \mathrm{SD}=0.54)$. Therefore, the perceived ease of use could be regarded as an inherent system property which does not 
affect either the perceived usefulness of an SBVR or the attitude towards using such an application.

In addition, the study investigated the effect of the task-technology fit as well as telepresence on the perceived usefulness. For the first time, our results demonstrate that SBVRs are very well suited to the performance assessment of hotels. The functionality of this technology makes it easier for the potential customer to gain an impression of a hotel, which positively affects the perceived usefulness. Moreover, our results show that telepresence has a significant effect on the perceived usefulness. Thus, virtual presence is an important factor that affects the perceived usefulness of an SBVR. Through the realistic presentation of a hotel, SBVRs are able to positively influence the feeling of being there, whereby both the hotel experience and the travel readiness of the potential guest can be increased (Choi et al., 2016; Klein, 2003).

\section{Practical implications}

In our study, we were able to demonstrate that SBVRs are suitable for performance assessment of hotels. The main advantage of this technology is that it offers a more efficient information gathering process, which makes sound decision-making possible. Due to the large number of available communication channels, hotel providers need to take a usercentric perspective to communicate the product information through appropriate channels. As the results of our study show, virtual reality applications are excellent marketing tools that can be used for information communication. The potential guest can better assess a hotel offer in the pre-purchase phase so that the risk of an information-related error decision is reduced. Above all, the feeling of being there reduces the inherent information asymmetry, which allows the user to quickly and easily obtain information. These findings have a direct impact on future hotel marketing. Through the use of virtual reality applications, the marketing managers can shorten the information acquisition process, which speeds up customer's purchase decision and increases the number of bookings.
Only virtual reality technology is currently able to create an intense, immersive user experience. Hotel providers and travel agencies should use this technological advantage for attractive presentation of their offers. Compared to traditional advertising methods, the potential guest can now do more than just imagine what a hotel stay would feel like. SBVRs turn the hotel presentation into an extraordinary experience in which the real experience of a hotel stay is conveyed to the potential guest virtually. A further advantage of SBVRs is that these applications can be used both online and offline as means of communication. By providing SBVRs on the hotel website as direct downloads or via established digital distribution channels (e.g. Google Play Store, Apple Store), a high coverage as well as easy access can be achieved. At local points of sale (e.g. travel agency, travel fairs), cheap virtual reality glasses (e.g. Google Cardboard) could be used as promotional gifts, which in combination with a smartphone can be used directly in a sales pitch as a sales-promoting marketing instrument. Another additional benefit of SBVRs is that the virtual hotel experience can be reproduced almost everywhere in consistent quality. After visiting a website or a travel agency, the potential guest can share relevant hotel information and the immersive hotel experience with other people (e.g. family, friends) who are involved in the booking decision process. Regarding the verifiability of advertising methods, the possibility of implementing a detailed user tracking is further very interesting for marketing purposes. By evaluating the user data, marketing managers can identify important key metrics such as points of interest of the hotel or interesting picture perspectives. Based on this data, it is possible to determine whether the view from the hotel balcony or the view into the hotel room (picture perspective) is more interesting for the potential guest and what significance (frequency, duration) additional hotel offers (e.g. spa, restaurant, sports facilities) have for the hotel presentation. This important usage information can also be used in the design of traditional advertising methods (e.g. catalogue, brochure) for the selection of appropriate pictures in order to further improve the attractiveness and effectiveness of these 
Virtual reality in the hotel industry: assessing the acceptance of immersive hotel presentation.

advertising methods. Due to these numerous advantages, we are firmly convinced that SBVRs are gaining in importance for hotel marketing in general and are becoming an integral part of virtual hotel presentations in particular. Hotel managers should therefore take this extraordinary type of hotel presentation into account when making future marketing investment decisions.

When developing SBVRs, hotel marketing managers should pay attention to the usability of the application. This should be as simple and intuitive as possible. In order to exploit the full potential of virtual reality applications, this requirement must also be taken into account. In contrast to internet applications, the user is hardly able to use additional input devices in SBVRs, so the interaction takes place on the basis of natural movement sequences alone. Consequently, in virtual reality, no unpredictable actions may occur which could adversely affect the user experience. In summary, we postulate that both the realistic visualisation of a hotel as well as the reproduction of familiar movement sequences are of fundamental importance for the usability of a virtual hotel application.

\section{Conclusions, limitations and future research}

For the basic explanation and prediction of the individual acceptance behaviour an extended TAM was used. Based on this model, we were able to present important findings that are relevant to both research and practice. For the first time, our study confirms that SBVRs are very suitable for the performance evaluation of hotels. SBVRs are considered by the potential customer as very good tools to obtain information on a travel accommodation. Compared to classic communication channels, the customer can obtain the required information more quickly and easily by using virtual reality applications. These efficiency advantages are essentially generated by the feeling of being there. Accordingly, the optical judgement contributes to the reduction of the information asymmetry of experience. Likewise, the results confirm that the virtual reality technology offers high usability for the potential customer. The primary intention when using virtual reality applications is to reduce possible uncertainties in the pre-purchase phase, thus minimising the risk of an information-related error decision for the customer.

Although our study provides important academic and practical insights into travellers' acceptance of SBVRs, the findings of our study are subject to some limitations. As previously mentioned, our sample is not in line with the demographic distribution of the German travelling public. Therefore, future studies should expand the sample size based on the demographic characteristics of the travelling public to provide a more general understanding of travellers' acceptance of SBVRs. Another limitation of the study is that despite the large sample size, all the participants had a similar cultural background. Therefore, it is possible that study results in other cultures may differ from our results. In particular, cultural differences regarding travel and leisure behaviour (e.g. number of holidays) could affect the technology acceptance behaviour of users. In this context, future research could examine the influence of cultural differences on technology acceptance. Due to the central role of the perceived usefulness, it would be interesting to identify further technology-related factors that influence the perceived usefulness. In this respect, for example, it would be interesting to examine whether the user can better assess the spatial conditions of a hotel by SBVRs compared to conventional visualisation forms, such as catalogues or internet images. Another research area concerns the evaluation of audio-visual elements to increase the immersive experience. In particular, the influence of sound and the integration of dynamic content (e.g. video) should be investigated in this context. It is also necessary to investigate how the use of a virtual reality application affects the decisionmaking process as well as the booking intention of the customer.

\section{References}

Ayeh, J.K., Au, N. \& Law, R. (2013). Predicting the intention to use consumer-generated media for travel planning. Tourism Management, 35, 132-143.

Barnes, S.J., Mattsson, J. \& Sørensen, F. (2016). Remembered experiences and revisit intentions. A longitudinal study of 
safari park visitors. Tourism Management, 57, 286-294.

Bertrand, M. \& Bouchard, S. (2008). Applying the technology acceptance model to $\mathrm{vr}$ with people who are favorable to its use. Journal of Cybertherapy and Rehabilitation, 1(2), 200-210.

Bilgihan, A., Kandampully, J. \& Zhang, T. (2016). Towards a unified customer experience in online shopping environments. International Journal of Quality and Service Sciences, 8(1), 102-119.

Bilgihan, A., Nusair, K., Okumus, F. \& Cobanoglu, C. (2015). Applying flow theory to booking experiences. An integrated model in an online service context. Information \& Management, 52(6), 668-678.

Buhalis, D. \& Law, R. (2008). Progress in information technology and tourism management. 20 years on and 10 years after the Internet - The state of eTourism research. Tourism Management, 29(4), 609-623.

Burdea, G. \& Coiffet, P. (2003). Virtual reality technology. Hoboken: John Wiley \& Sons.

Burton-Jones, A. \& Hubona, G.S. (2005). Individual differences and usage behavior: revisiting a technology acceptance model assumption. The DATA BASE for Advances in Information Systems, 36(2), 58-77.

Chang, H. (2010). Task-technology fit and user acceptance of online auction. International Journal of Human-Computer Studies, 68(1-2), 69-89.

Cheng, S. \& Cho, V. (2011). An Integrated Model of Employees' Behavioral Intention Toward Innovative Information and Communication Technologies in Travel Agencies. Journal of Hospitality \& Tourism Research, 35(4), 488-510.

Chin, W.W. (1998). The partial least squares approach for structural equation modeling. In Marcoulides, G.A. (eds.) (1998). Modern methods for business research. Mahwah: Lawrence Erlbaum Associates Publishers, 295-336.

Cho, J. \& Lee, J. (2006). An integrated model of risk and risk-reducing strategies. Journal of Business Research, 59(1), 112-120.

Choi, J., Ok, C. \& Choi, S. (2016). Outcomes of Destination Marketing Organization Website Navigation. The Role of
Telepresence. Journal of Travel \& Tourism Marketing, 33(1), 46-62.

Chung, N., Han, H. \& Joun, Y. (2015). Tourists' intention to visit a destination: The role of augmented reality (AR) application for a heritage site. Computers in Human Behavior, 50, 588-599.

Cruz-Neira, C., Sandin, D.J. \& DeFanti, T.A., (1993). Surround-screen projection-based virtual reality: the design and implementation of the CAVE. In Whitton, M.C. (1993). Proceedings of the 20th annual conference on Computer graphics and interactive techniques. New York: ACM, 135-142.

Davis, F.D. (1989). Perceived Usefulness, Perceived Ease of Use, and User Acceptance of Information Technology. MIS Quarterly, 13(3), 319-340.

Davis, F.D., Bagozzi, R.P. \& Warshaw, P.R. (1989). User Acceptance of Computer Technology: A Comparison of Two Theoretical Models. Management Science, 35(8), 982-1003.

Debbabi, S., Daassi, M. \& Baile, S. (2010). Effect of online 3D advertising on consumer responses: the mediating role of telepresence. Journal of Marketing Management, 26(9-10), 967-992.

Dishaw, M.T. \& Strong, D.M. (1999). Extending the technology acceptance model with task-technology fit constructs. Information \& Management, 36(1), 9-21.

Fishbein, M. \& Ajzen, I. (1975). Belief, attitude, intention and behavior: An introduction to theory and research. Reading: AddisonWesley.

Fornell, C. \& Larcker, D.F. (1981). Evaluating Structural Equation Models with Unobservable Variables and Measurement Error. Journal of Marketing Research, 18(1), 39-50.

Fuchs, P., Moreau, G. \& Guitton, P. (2011). Virtual reality: Concepts and technologies. Balkema: CRC Press.

Geisser, S. (1974). A Predictive Approach to the Random Effect Model. Biometrika, 61(1), 101-107.

Goldman Sachs (2016). Virtual \& Augmented Reality: Understanding the race for the next computing platform. Equity Research. Goldman Sachs. URL: http://www.gold mansachs.com/our-thinking/pages/ 
technology-driving-innovation-folder/virtual -and-augmented-reality/report.pdf (Accessed 05.02.2018).

Goodhue, D.L. \& Thompson, R.L. (1995). TaskTechnology Fit and Individual Performance. MIS Quarterly, 19(2), 213-236.

Guttentag, D.A. (2010). Virtual reality: Applications and implications for tourism. Tourism Management, 31(5), 637-651.

Hair, J.F., Ringle, C.M. \& Sarstedt, M. (2011). PLS-SEM: Indeed, a Silver Bullet. The Journal of Marketing Theory and Practice, 19(2), 139-152.

Hair, J.F., Babin, B.J., Anderson, R.E. \& Black, W.C. (2014). Multivariate data analysis. Harlow: Pearson.

Hair, J.F., Hult, G.T.M., Ringle, C.M. \& Sarstedt, M. (2017). A Primer on Partial Least Squares Structural Equation Modelling (PLS-SEM). London: Sage Publications.

Henseler, J., Hubona, G. \& Ray, P.A. (2016). Using PLS path modeling in new technology research: updated guidelines. Industrial Management \& Data Systems, 116(1), 2-20.

Henseler, J., Ringle, C.M. \& Sarstedt, M. (2015). A new criterion for assessing discriminant validity in variance-based structural equation modeling. Journal of the Academy of Marketing Science, 43(1), 115-135.

Hoehle, H. \& Huff, S. (2012). Advancing TaskTechnology Fit Theory: A formative measurement approach to determining task-channel fit for electronic banking channels. In Hart, D.N. \& Gregor, S.D. (eds.) (2012). Information Systems Foundations: Theory Building in Information Systems. Canberra: ANU Press, 133-170.

Hu, P.J., Chau, P.Y.K., Sheng, O.R.L. \& Tam, K.Y. (1999). Examining the Technology Acceptance Model Using Physician Acceptance of Telemedicine Technology. Journal of Management Information Systems, 16(2), 91-112.

Huang, Y.-C., Backman, S.J. \& Backman, K.F. (2012). Exploring the impacts of involvement and flow experiences in Second Life on people's travel intentions. Journal of Hospitality and Tourism Technology, 3(1), 4-23.
Huang, Y.-C., Backman, S.J., Backman, K.F. \& Moore, D. (2013). Exploring user acceptance of $3 D$ virtual worlds in travel and tourism marketing. Tourism Management, 36, 490-501.

Huang, Y.-C., Backman, K.F., Backman, S.J. \& Chang, L.L. (2016). Exploring the Implications of Virtual Reality Technology in Tourism Marketing. An Integrated Research Framework. International Journal of Tourism Research, 18 (2), 116-128.

Hwang, Y.-H., Jani, D. \& Jeong, H.K. (2013). Analyzing international tourists' functional information needs: A comparative analysis of inquiries in an on-line travel forum. Journal of Business Research, 66(6), 700705.

Hyun, M.Y. \& O'Keefe, R.M. (2012). Virtual destination image: Testing a telepresence model. Journal of Business Research, 65(1), 29-35.

Jiang, Z. \& Benbasat, I. (2007). Investigating the Influence of the Functional Mechanisms of Online Product Presentations. Information Systems Research, 18(4), 454-470.

Kim, H.-C. \& Hyun, M.Y. (2016). Predicting the use of smartphone-based Augmented Reality (AR): Does telepresence really help? Computers in Human Behavior, 59, 28-38.

Kim, J. \& Forsythe, S. (2008). Adoption of Virtual Try-on technology for online apparel shopping. Journal of Interactive Marketing, 22(2), 45-59.

King, W.R. \& He, J. (2006). A meta-analysis of the technology acceptance model. Information \& Management, 43(6), 740-755.

Klein, L.R. (2003). Creating virtual product experiences: The role of telepresence. Journal of Interactive Marketing, 17(1), 4155.

Klopping, I.M. \& McKinney, E. (2004). Extending the Technology Acceptance Model and the Task-Technology Fit Model to Consumer E-Commerce. Information Technology, Learning, and Performance Journal, 22(1), 35-48.

Kourouthanassis, P., Boletsis, C., Bardaki, C. \& Chasanidou, D. (2015). Tourists responses to mobile augmented reality travel guides: The role of emotions on 
adoption behavior. Pervasive and Mobile Computing, 18, 71-87.

Lam, T., Cho, V. \& Qu, H. (2007). A study of hotel employee behavioral intentions towards adoption of information technology. International Journal of Hospitality Management, 26(1), 49-65.

Law, R., Buhalis, D. \& Cobanoglu, C. (2014). Progress on information and communication technologies in hospitality and tourism. International Journal of Contemporary Hospitality Management, 26(5), 727-750.

Lee, D.Y. \& Lehto, M.R. (2013). User acceptance of YouTube for procedural learning: An extension of the Technology Acceptance Model. Computers \& Education, 61, 193-208.

Lee, H.-H., Fiore, A.M. \& Kim, J. (2006). The role of the technology acceptance model in explaining effects of image interactivity technology on consumer responses. International Journal of Retail \& Distribution Management, 34(8), 621-644.

Lee, S.Y. (2014). Examining the factors that influence early adopters' smartphone adoption. The case of college students. Telematics and Informatics, 31(2), 308318.

Legris, P., Ingham, J. \& Collerette, P. (2003). Why do people use information technology? A critical review of the technology acceptance model. Information \& Management, 40(3), 191-204.

Liu, Y., Li, H. \& Carlsson, C. (2010). Factors driving the adoption of m-learning: An empirical study. Computers \& Education, 55(3), 1211-1219.

Marangunić, N. \& Granić, A. (2015). Technology acceptance model: a literature review from 1986 to 2013. Universal Access in the Information Society, 14(1), 81-95.

Marasco, A., Buonincontri, P., van Niekerk, M., Orlowski, M. \& Okumus, F. (2018). Exploring the role of next-generation virtual technologies in destination marketing. Journal of Destination Marketing \& Management, 9, 138-148.

Morris, B. (2017). Facebook Sets Goal of a Billion Virtual-Reality Users, Unveils New Headset. The Wall Street Journal. URL: https://www.wsj.com/articles/facebook- sets-goal-of-a-billion-virtual-reality-usersunveils-new-headset-1507764852

(Accessed 26.01.2018).

Nance, W.D. \& Straub, D.W. (1996). An Investigation of Task/Technology Fit and Information Technology Choices in Knowledge Work. Journal of Information Technology Management, 7(3-4), 1-14.

Nowak, K.L. \& Biocca, F. (2003). The Effect of the Agency and Anthropomorphism on Users' Sense of Telepresence, Copresence, and Social Presence in Virtual Environments. Presence, 12(5), 481-494.

Ok, C., Shanklin, C.W. and Back, K. (2008). Generalizing Survey Results from Student Samples. Implications from Service Recovery Research. Journal of Quality Assurance in Hospitality \& Tourism, 8(4), 1-23.

Okumus, F., Bilgihan, A., Ozturk, A.B. \& Zhao, $X$. (2017). Identifying and overcoming barriers to deployment of information technology projects in hotels. Journal of Organizational Management, 30(5), 744-766.

Park, S.Y. (2009). An Analysis of the Technology Acceptance Model in Understanding University Students' Behavioral Intention to Use e-Learning. Educational Technology \& Society, 12(3), 150-162.

PriceWaterhouseCoopers (2017). Virtual reality. Global entertainment and media outlook 2017-2021: Curtain up! User experience takes centre stage. PriceWaterhouseCoopers. URL: https://www.pwc.com/gx/en/industries/ente rtainment-media/outlook/segment-

insights/virtual-reality.html

(Accessed 09.02.2018).

Rauniar, R., Rawski, G., Yang, J. \& Johnson, B. (2014). Technology acceptance model (TAM) and social media usage. An empirical study on Facebook. Journal of Enterprise Information Management, 27(1), 6-30.

Reinhardt, U. (2018), Tourismusanalyse 2018, Hamburg.

Sanchez-Vives, M.V. \& Slater, M. (2005). From presence to consciousness through virtual reality. Nature reviews. Neuroscience, 6(4), 332-339. 
Virtual reality in the hotel industry: assessing the acceptance of immersive hotel presentation.

Sharifpour, M., Walters, G., Ritchie, B.W. \& Winter, C. (2014). Investigating the Role of Prior Knowledge in Tourist Decision Making: A Structural Equation Model of Risk Perceptions and Information Search. Journal of Travel Research, 53(3), 307322.

Shim, S.I. in \& Lee, Y. (2011). Consumer's perceived risk reduction by $3 \mathrm{D}$ virtual model. International Journal of Retail \& Distribution Management, 39(12), 945959.

Soopramanien, D.G.R., Fildes, R. \& Robertson, A. (2007). Consumer decision making, Ecommerce and perceived risks. Applied Economics, 39(17), 2159-2166.

Steuer, J. (1992). Defining Virtual Reality: Dimensions Determining Telepresence. Journal of Communication, 42(4), 73-93.

Stone, M. (1974). Cross-Validatory Choice and Assessment of Statistical Predictions. Journal of the Royal Statistical Society. Series B (Methodological), 36(2), 111-147.

Subramanian, G.H. (1994). A Replication of Perceived Usefulness and Perceived Ease of Use Measurement. Decision Sciences, 25(5-6), 863-874.

Taylor, J.W. (1974). The Role of Risk in Consumer Behavior. Journal of Marketing, 38(2), 54-60.

Tussyadiah, I.P., Wang, D. \& Jia, C. (2017). Virtual Reality and Attitudes Toward Tourism Destinations. In Schegg, R. \& Stangl, B. (eds.) (2017). Information and Communication Technologies in Tourism 2017. Cham: Springer International Publishing, 229-239.

Tussyadiah, I.P., Wang, D., Jung, T.H. \& tom Dieck, M. (2018). Virtual reality, presence, and attitude change. Empirical evidence from tourism. Tourism Management, 66, 140-154.
Venkatesh, V. (2000). Determinants of Perceived Ease of Use: Integrating Control, Intrinsic Motivation, and Emotion into the Technology Acceptance Model. Information Systems Research, 11(4), 342-365.

Venkatesh, V., Morris, M.G., Davis, G.B. \& Davis, F.D. (2003). User Acceptance of Information Technology: Toward a Unified View. MIS Quarterly, 27(3), 425-478.

Venkatesh, V. \& Bala, H. (2008). Technology Acceptance Model 3 and a Research Agenda on Interventions. Decision Sciences,39(2), 273-315.

Venkatesh, V. \& Davis, F.D. (2000). A Theoretical Extension of the Technology Acceptance Model. Four Longitudinal Field Studies. Management Science, 46(2), 186-204.

Venkatesh, V., Thong, J.Y.L. \& Xu, X. (2012). Consumer acceptance and use of information technology. Extending the unified theory of acceptance and use of technology. MIS Quarterly, 36(1), 157-178.

Xiang, Z., Magnini, V.P. \& Fesenmaier, D.R. (2015). Information technology and consumer behavior in travel and tourism: Insights from travel planning using the internet. Journal of Retailing and Consumer Services, 22, 244-249.

Zhou, L. \& Lin, Q. (2012). Virtual tour's impact on destination image. In Wei, J. (eds.) (2012). ISMOT 2012: proceedings of the 2012 IEEE International Symposium on Management of Technology. Piscataway: Institute of Electrical and Electronics Engineers, 641-643. 